\title{
$\widehat{A}$ Madridge \\ madridge Journal of Cancer Study \& Research \\ Interconnecting Scientific World
}

Review Article

Open Access

\section{The Multicellular Origin of Cancer and the Evolution of Oncogenesis}

\author{
Mahmut M Karindas* \\ Clinical and Molecular Oncologist, President, WAMS The World Academy of Medical Sciences, Netherlands
}

\section{Article Info}

\section{${ }^{*}$ Corresponding author:}

Mahmut M Karindas

Clinical and Molecular Oncologist President WAMS The World Academy of Medical

Sciences

Netherlands

E-mail:m.karindas@wams.academy

Received: February 10, 2017

Accepted: May 5, 2017

Published: June 27, 2017

Citation: Karindas MM. The Multicellular Origin of Cancer and the Evolution of Oncogenesis. Madridge J Cancer Stud Res. 2017; 1(1): 1-7.

doi: $10.18689 / \mathrm{mjcsr}-1000101$

Copyright: () 2017 The Author(s). This work is licensed under a Creative Commons Attribution 4.0 International License, which permits unrestricted use, distribution, and reproduction in any medium, provided the original work is properly cited.

Published by Madridge Publishers

\begin{abstract}
Cancer cells are the result of the multi-step, multi-dimensional and multi-generational process of oncogenesis, but they are never the products of cellular transformation. When a stem cell divides, asymmetrically or symmetrically, it produces two new (new generation) cells, a differentiated daughter cell and a daughter which is a parent-identical stem-cell, or two identical daughter stem cells, respectively. In either case, the daughter cells, differentiated or parent-identical, have their own individuality and character. A daughter cell is not a transformed parent cell; it has its own cellular identity, genotype and phenotype although it carries its parent's genotypical and phenotypical features. In today's oncology research literature the term cellular transformation, which only technically refers to neoplastic cellular changes, is unintentionally amiss, but scientifically delusive; it implies a solitary cellular reign that misleadingly suggests a single cell origin for oncogenesis. The term has never been used to literally mean tissue transformation, yet in point of fact it fatefully describes and invariably reveals tissue transformation which, as a term, must practically replace the term cellular transformation.

In any living multicellular organism, whose multicellular existence and functionality is totally based on intercellular subsistence, a multicellular act or happening is absolutely impossible to start with or from a solitary cell action. In multicellular organisms, in vivo, malignant neoplasms, including leukemias, which all are the products of highly organized cellular teamwork from the very beginning, never arise from single cells; they arise from groups of cells.
\end{abstract}

Keywords: Oncogenesis, Evolution of oncogenesis, Malignant transformation, Multicellular origin of cancer, Cancer stem cell, Dormancy, Microenvironment, Metastasis

\section{The Definition of Oncogenesis}

The human cell is mankind's basic unit of life and a dynamically functional, highlyorganized, self-governed component of human body. It is the condition of this excellent micro-unit of tissue that determines the state of the health of the host organ and body. Somatic cells live with the guidance of a "Cell Cycle" through which their status as well as their internal and external conditions, circumstances and contingencies are meticilously monitored and controlled. Holding the intracellular executive power and command, DNA governs the absolute soverignty of the cell and controls its internal and external behaviors, functions, committments, transactions and affairs. Meanwhile, performing specific and specialized functions and duties of their own in a highly harmonious cooperation, the main molecules of this tiny elementary compartment of human organism, proteins, nucleic acids, carbohydrates and lipids work together to build its organic, structural and inherent parts, elements, features and characteristics. 
As their name suggests, cellular organisms are organized living establishments. While a unicellular living organism is neatly organized in itself, a multicellular one is highly organized not only in its tiny constituent unit, the cell, but also across its whole multi-component, multi-tissue, multi-organ and multi-system structure. Behind the powerful look and omnipotent nature of this immense organization of multicellularity, however, which is made of quite impregnable, infallible and structurally and functionally collaborative assemblies, there are highly detailed, delicately integrated cellular compositions that are sensitive to intracellular, intercellular and extracellular changes and vulnerable to any internal or external threat to the cell's strict inner order and to its harmonious relations with its siblings and neighboring cells, as well as its relationship with its extracellular matrix $(E C M)$ and with the rest of the microenvironment.

Set to function physiologically and strategically to preserve the organism's welfare and livelihood, being given life and duty to keep the cell's stably prosperous and providential state, these compositions work as dedicated enterprises run by faithful artisans and toilers. The most typical and spectacular example of this is the human body, a masterpiece of bioarchitecture and bioengineering. This flawless, model multicellular organism, the excellence of bio-formation we take for granted, however, encounters more problems than the planet's other species of living organisms do. Some of these problems are unfortunate and ruthless enough to have the organism rendered defenseless and cast a shadow over its undisputed infallibility. The human cell, where a dramatically destructive set of happenings, neoplasia, as the most vicious one of these problems, begins, is ironically also the place where its corporate burocracy and supreme command is stationed. Despite the fact that the DNAgoverned cellular behavior is performed impeccably, the cell may any time happen to encounter certain unfavorable situations that may individually or jointly affect its perfect governance in various sectors and at various levels.

The persistence of such situations and their effects usually bring about unpropitious consequences that seriously intimidate or threaten the divinity and harmony of the cell's regime and order. Then a sequence of cytological changes through a series of interacting and inter-effecting cellular and tissue processes follows across the microenvironment. Unless there is an interruption or halt, this culmination of happenings brings to the scene an unfortunate, ill-bred progression which will have then already begun to ensconce around: oncogenesis.

\section{The Basis of Oncogenesis}

In a living multicellular organism, nothing is purposeless or by chance; intracellularly or extracellularly, nothing usual or expected can happen without a purpose, and nothing unusual or abnormal can occur without a reason. In our bodies, we get more than 0.5 trillion of our cells replaced daily. At any given moment in a human body, which is made of around 75-100 Trillion cells, there are 5-6 Trillion actively dividing cells among which there are billions of them that are either ready to go through mutations, or going through mutations. And billions of others are already mutated and highly prone to further mutations that may emerge any moment which is the case more in adult human bodies than young ones and more dramatically in-effect in the aging ones.

Mutations bring cells immediate alienation in the tissue and make them become singled-out solitarily or multiply in groups. Such cells, solitary or in groups, mostly become dormant or undergo apoptosis before they find time to organize themselves to multiply and thrive. Larger groups sometimes show the power and organizational capacity to organize, but, they still have no guarantee for a foreseeable future for fortune.

Human body is not a product of ordinary engineering and does not allow in its domains any unauthorized inauspicious acts to have a go as they please. In such an immaculate organismic construction, our lives are not left in a biomolecular destiny where the fate is determined by chances or freaks, and that is why, not all mutations or series of mutations lead their cell groups to the genesis of neoplasm. And any neoplastic occurence that makes it in no way means that it has been given the authorization to proceed; it will not be left alone so easy, at least not before facing all the consequences and countermoves.

A malignant process is essentially based on and a product of the ordinary cellular and tissue biology, and the impending malignant cells of this insidious phenomenon, the new kids on the block, are in fact as much body property as the regular cells around, and just like the regular cells, they statutorily belong to the tissue. Also, they are not, when they first emerge, meant to be the assailants or adversaries of the prime tissue or its mannerly loyal regular (prime) cells and elements; on the contrary, they, at least originally, are produced and allowed to act and function like the regular cells that they begin to supplant, and they are given rights, privileges and duties just like the regular cells of the territory.

Although, at the beginning, it is a mutually-established cellular happening within the expected standards and reasonable limits of tissue physiology and homeostasis and is no less than explainable by the natural laws of human biology, the oncogenic event progresses amiss to become a unfavorable event and then an unwanted escapade.

Cellular proliferation by division and differentiation processes are arranged, programmed and executed through an immense range of interconnecting intracellular, intercellular and extracellular signaling networks which are the livelihood of the elemental constituents of human infrastructure from the embriologic period to the end of lifetime. In this wholesome natural phenomenon of existence, an oncogenetic development emerges as an ultimately conflicting, confusing and disorganizing occurrence with dramatic imposition, and brings out bands of new cells, the neoplastic cells, which impudently crop up ultimately demanding full habitation which they do their best to make eventually unconditional.

Seeing well that their fresh existence proves quite contingent upon arrival, they in no time go through some big efforts to achieve two painstaking tasks which they immediately realize they should fulfill for their survival: 1. Organizing a no- 
default governance for themselves, 2. Establishing some mutual communal relationship with the environment as trouble-free as possible aiming to make it at least indulgent and permissive if not interactive. Their main goal is to survive, not necessarily to invade. Their demand for settlement receives in the first instance an instinctive embrace in the tissue's microenvironment as they are naturally far from being considered strangers at that stage. But, as they begin to show their oddity, which soon turns into some boldly-dramatized unconformity, the callow embrace they have already been given leaves its place to a state of gradual, reluctant tolerance which will be existing for a considerable period. But they settle in the way they find suitable for themselves anyway. Because of their dissociative disposition and behavior, the recognition of their full settlement and their integration to the territory soon becomes difficult to materialize as the prime tissue eventually sees the dramatically increasing lack of structural and functional coordination with this nolonger-favorable horde of newcomers, and the increasing necessity to cope with their burden with ever-increasing incompatibility and discordance. That eventually induces the prime tissue to consider a full mobilization of all its available means of preserving and defending its own livelihood, welfare and order while dealing with this disappointing and increasinglyburdening situation which soon proves to be a predicament going far beyond its expectation or readiness. Before long, the body's immune system also becomes aware of the situation and gives the prime tissue the hint that all the tissue-wide, bodily means of defense and order are to be mobilized apace to suppress the emerging disequilibrium which has been becoming more obvious to inevitably cope with. The whole matter here is nothing other than a base for clone-colony actions and movements through which the neoplastic cells' efforts for survival change their mode to "invade to survive", and then to "invade and destroy to survive". From then on, the confrontation turns into a wholesome showdown between the groups of the conflicting sides where solitary cells of either side, can never be able to act, function or fight alone.

\section{No grounds for solitary cells}

In the human multicellular organism, no single cell of any kind can initiate a normal or abnormal group act or function by its own. A solitary cellular act or behavior, should it even be practically possible, would have no value or meaning in the microenvironment it dwells in, and no significance to the organism it belongs to, simply because it can not pursue any objective on its own, it would not achieve an aim, and it would not reach a goal. Its individual cellular performance with acts, functions and activities are meaningful and countable only in its own cell Group (population) where it can live and collaborate with the other cells [11].

In a multicellular organism, under optimum circumstances, no cell can be looked upon or reckoned with in any way as solitary, and neither can it be apportioned as such. A mutated cell usually belongs to a population of mutant cells. Although, like the other cells in the group, it is a cell of interest oncogenetically, it bears no significance or exclusivity in its newly altering state and it is far from tolling any bells yet for a future oncogenetic happening. When these cells' mutational modifications amplify and add up through generations, they breed flourishing populations of new-generation cells (subclones) which rapidly become the current holders of the substance and weight of the accumulated potent mutations.

A solitary cell of accumulated mutation, regardless of its phenotypical-genotypical status, or its privileges in functionality, like an ordinary cell, has recruitment and attraction capability in its population. To put its ability in life, this ultimately mutated high-potential cell, has to be in conformity with the rest of its population. Without this hardto-achieve conformity with the fellow cells, it has no chance of thriving; furthermore, it gets alienated and eventually becomes unoriented having tough time for survival. This state of affairs is shared by (that is, individually applies to) all the other cells of the population with no exception. The achieved conformity with the group is the beginning of everything. From that point on, the "defined and established" group act shows off boldly, and soon becomes the prime tissuess enigma and the immune system ss bad news. The main issue now is the alteration in the inner subpopulation affairs which involve the adaptation to the emerging rough conditions, dealing with the outcomes and facing the harsh consequences. From then on, the prime goal of the subpopulation is to keep and use all the available means and instrumentation for survival.

In a multicellular organism, any cellular act, action, reaction or function is planned, arranged, materialized and performed on the basis of a multicellular, communal constitution which sets strict rules and regulations that are administered stringently. Normal or abnormal, there can be no single cell in a multicellular organism, that has, genotypically or phenotypically, any exclusive singular status in terms of livelihood or functionality, and therefore no cell of any kind, favorable or unfavorable, has any particular privilege or power to act or function solitarily. Being a main part of the duty performed by a highly organized commune cellular collaboration, good or bad cellular attitudes in the chaotic oncogenetic process are the joint product of cells' indivudually contributed work and giving, and has no input that directly comes from any single-cellular initiative.

\section{Cancer cells are rather the products of malignant tissue transformation than malignant cellular transformation}

Cancer cells are not the transformation of the cells that preceed them. In or between multiple generational steps that take place between normal or abnormal new cells of any kind and their ancestors of generations, there is a series of successive offspring with progressive undifferentiation, but there is no cellular transformation. Referring to the last generational step of oncogenesis, some scientists describe the malignant transformation as a cellular transformation. In the multiple generational stages in oncogenesis, cancer can not be described as a cellular transformation. 
If we must talk about a transformation in oncogenetic process, to avoid wrong interpretative trajectories in research work at large, we should rather entitle itmalignant tissue transformation, than malignant cellular transformation. Cells do not just become cancerous, and they do not transform into neoplastic cells; they get mutated and breed mutated cells. Malignant transformation is the territorial progression through which the properties of neoplasm are progressively acquired by each new generation of cells which, through that progression, never have any individual transformation.

A cellular transformation, if it could be described, would be a cell's transforming into a different genotype or phenotype or both, changing from one shape, nature and identity to another while remaining in its self. We see such a model of cell, in vivo, neither in a neoplastic tissue nor in a normal one. When a cell's DNA has a change or damage, the cell gets mutated, not transformed. If that cell lives on to breed, generating its own daughter cells which produce newer lines of clones, it contributes, with genetic and epigenetic effects, to the ever-changing landscape of the microenvironment; such a change is biologically possible only in breeding, and breeding is not a cellular transformation but a dramatic input into a "malignant tissue transformation" which is the everpresent battlefield of the warring powers of oncogenesis.

When a stem cell divides, asymmetrically or symmetrically, it produces two new (new generation) cells, a differentiated daughter cell and a daughter which is a parent-identical stemcell, or two identical daughter stem cells, respectively. In either case, the daughter cells, differentiated or parent-identical, have their own individuality and character. A daughter cell is not a transformed parent cell; it has its own cellular identity, genotype and phenotype although it carries its parent's genotypical and phenotypical features. The term cellular transformation in today's medical research literature, which technically refers to neoplastic cellular changes, is unintentionally amiss, but scientifically delusive; it implies a solitary cellular reign that misleadingly suggests a single cell origin for oncogenesis. The term has never been used to literally mean tissue transformation, yet in point of fact it fatefully describes and invariably reveals tissue transformation which, as a term, must practically replace the term cellular transformation.

\section{The overwhelming tissue transformation is the oncogenesis itself}

In its ever-changing and evolving neoplastic environment, a full-blown neoplastic tumor makes the body go through an enormously progressive multi-range series of events while evolving a way and style of its own ultimately turning the whole process into its own escapade.

Cancer cells, the cells of abnormal new growth coming from several generations of parentage, are new-generation cells emerging in the neoplastic stage of oncogenesis as the ultimate offsprings of a long, differential linage of cells involved in a series of amplifying intracellular changes incited by various factors or elements and then in ensuing extracellular eventualities. Within this frame, we see the neoplastic transformation as an uncontrolled cellular proliferation with an increasing mutational complexity and a pathologic cellular growth that results from the accumulation of myriad genetic mutations [12]. This throng opens way to cascades of happenings that overpower positions, situations as well as points of balance and control via or at multitudes of junctures bringing scores of molecular and morphologic consequences at the expense of the organism. The heterogeneity of the cells of this metamorphosis, resulted by the cells' mutational amplification and complexity, eventually helps the emerging colonies of natural selection outplay the nonpermissive microenvironment.

In relation to natural selection, a key mechanism of evolution [1], as Merlo, Pepper and Graves [2-4] observe, the fundamentals of cancer has been validated as a complex, Darwinian, adaptive system. We can further state that natural selection is the exact model of the evolutionary selection in oncogenesis. The all-the-way transformation of tissues along the trans-generational oncogenetic process follows the pattern that we see in natural transformation in species at large [13]. Acting on the phenotype whose genetic basis gives a reproductive advantage to certain populations that specialize for particular niches, natural selection eventually results in generated new speices; this is exactly what we see in clonal expansion of cancer where cancer cells evolve by natural selection which propels the fittest forward to compete through the oncogenetic progression. While destroying cancer clones in this progression, and eroding their habitats, oncotherapy inadvertently provides a potent selective pressure for the expansion of resistant variant clones. This facet of the Darwinian character of oncogenesis is currently the primary impediment to the universal oncotherapy on all fronts.

\section{The main players, opponents and proponents are the Clonal Cell Groups}

While we describe tumors as abnormal tissue, we must not see them as alien structures, because they simply are not. They belong to the body as much as a normal tissues do and they come from exactly where normal tissues do. Their recapitulating the outgrowth and differentiation patterns of normal tissues is not a clever, insidious skill they create and perform, but an ability and power out of the proficiency they are inheritably granted.

The changing environment of a tissue riddled by a neoplastic activity brings an enormous volume of plays and players to the scene. As this oncogenetic process is a clonal evolution from the start, only successively emerging various clones give rise to the progression in which, from the very beginning, an exclusively privileged status of power or function for a single cell is never possible. While there are many different plays and a multitude of dedicated players in each of the contending powers through the whole oncogenetic progression, there is no shared play between them. 
Being realistically in the same niche as normal stem cells, the stem cells of malignant tumors, cancer stem cells (CSCs), have two tasks to do for their groups: keeping their groups as thriving and going as possible, and engaging in a strictly "nocompromise" neighborhood relationship with the prime tissue on a mutual but "everybody-their-own-way" basis. Their restless furtherance without a break is not totally a misuse of the the prime tissue's profuse tolerance and hospitality, but a matter of their own strict task and agenda which they can not afford to neglect simply because they have to survive.

The clonal evolution of the Oncogenetic Process begins well before the tumorigenic cell groups' entry into the introduction-turned-confrontation stage in the niche whose ever-changing life is lived and experienced by all that are in it. The disruption of growth regulation, the main molecular consequence of the progressively continuing mutations, soon brings the next consequence along: The loss of the control of proliferation, differentiation and apoptosis. It becomes quite difficult for the microenvironment and its prime tissue to close eyes to that latest turn which is also the most critical one. From that moment on the whole microenvironment turns into a battlefield for an all-out multi-power clash in which, not only the opposing sides, the clones and the prime cell population, but also the clones among themselves ultimately declare survival war on one another.

\section{Metastasis is not quite a scheduled end of the Oncogenetic Evolution}

The epic journey of oncogenesis is an evolution that is not programmed to end with metastasis. Could a terminally ill human body with an aggressive metastatic tumor somehow be able to live on, the oncogenetic evolution would have continued with tertiary, quaternary and quinary tumors, and so forth. But hardly living their "secondary" stage of multigenerations, almost all tumors prematurely see the end of their evolvement, passing away along with the organisms they kill.

A primary tumor's genomic instability persists in metastasis not just frequently [5] but always. The sequence of the growth advantage metastatic cells gain through accumulated mutations takes place with the same means and mechanisms as the ones we see with primary tumors. In the microenvironment of a metastatic tumor, with some exceptions, most of the conditions of the neoplastic progression are identical with the ones seen in the primary tumor's microenvironment. In metastatic tumors, we see the same consequences of being a solitary cell exactly as the ones in primary tumors.

The selective pressures and conditions of the changing environment and immune system with warrants and sanctions ultimately define the fittest of the outcompeting cell groups. As conventionally agreed upon, it is the survival of the strongest. But, contrary to another conventional opinion, it is not "every cell for itself". Just like the primary tumor's own environment, the territory of the metastatic neoplastic progression is a platform where metastatic cells' destinies are determined as either dormant state or tumor progression, or apoptosis. As one of the striking main features of metastatic tumors, the genetic heterogeneity of metastases reflects heterogeneity already existing within the primary tumor which is a mixture of numerous subclones each of which has independently expanded to constitute a large number of their own cell groups [6].

While the tissue's healthy cells together act as a microenvironmental control system to prevent the development and progression of emerging tumor cells [7], all the cells without exception get variably involved in the countless molecular and biomolecular transactions and alterations by which they all get their development, prosperity, maintenance and affluence effected one way or another. The responsibilities, obligations and liabilities carried out by the overseeing tissue governance in metastases are exactly the ones that are observed in the primary tumor's microenvironment. Just like the way it happens in the primary tumor microenvironment, a metastatic domain can in no way allow any exception for any particular cell within the territory. So, just like the primary tumor's microenvironment, the microenvironment of the metastatic tumor executes the same strict rules which no cell can overcome solitarily.

Through the evolutionary process of neoplastic tumors, the natural selection leans on phenotypic variability generated by the accumulation of genetic, genomic and epigenetic alterations [8]. The deriving productive aggressive phenotypes, however, take quite a time to take hold. With an average doubling time of 20-40 hours [9], newly produced cancer cells are basically not robust enough to live their younger days successfully in terms of survival, and most of them die before they can manage to carry out their own divisions, which is the reason it takes some time for any primary or metastatic tumor to fully establish itself as equipped to the hilt. This reflects the fact that the pursuance of neoplastic formation, both primary and metastatic, is an affair of clonal expansion with clonal selection, and ultimately a matter of clonal wars where solitary cells of commitment, ascendancy or eloquence have yet to conform to integrate or get doomed to destruction.

By having mutations shared by no other cells, solitary cells lose their fight for survival as soon as the fact that they are limited in the long term to fully meet the conditions to fit in becomes apparent and gets discovered by the regime to which the solitariness is nothing more than redundant presence within the multi-power, multi-pressure and multiliability commune of integral significance and values which is in an ongoing state of conflict and clashes for differences to equalize and exchanges to compromise.

Cancer cells' genotypical, phenotypical and biological heterogeneity, which collectively brings intraclonal and microenvironmental mechanization and mobility, is directly proportional to their ultimate individual and colonial invasiveness and metastatic ability both in primary tumors and metastases. In order to live with a guaranteed future in a metastatic niche, disseminated cancer cells should land there in clusters or in assembling groups, not necessarily at the same time, but within a certain short period of time. 
Just grouping, however, to have a decent settlers life, is not sufficient; in addition to the abilities they have, they should generate and acquire capabilities that are necessary to confront and overcome the new barriers of the unpermissive microenvironment while organizing themselves to form an aggressive colony. Their fate mainly depends on their own qualities and capabilities while, in part, they are under the effects of microenvironment's signaling system to which they principally do their best not to succumb.

If a metastatic cancer cell lands in a new location solitarily and remains so for 12-18 hours without having a chance to perform reproductive activity, it becomes dormant or undergoes apoptosis. If a solitary metastatic cell is the only tumor cell that has landed in a distant tissue site, whatever productive and aggressive capacity and capability it may have, it will be forced to dormancy or apoptosis. Should it be quick and smart enough to keep the control and pressure mechanisms of the microenvironment busy and therefore earn time to go into mitosis, which is its only goal anyway, its daughters, the ones which would be more difficult cells for the microenvironment's governing power to suppress, would in fact be the problem the microenvironment is intimidated by. That's why, under normal circumstances, that would not be the case as the indisputable power of the microenvironment would not allow such a trivial settlement to become a threat.

If two or more solitary metastatic tumor cells land in a distant tissue site together at the same time or in succession and close enough to each other, they engage in communication using their exosomes. Unless they become dormant or undergo apoptosis, they quickly team up to flourish and multiply to create a micrometastasis. But reaching their goal is not easy if they are from different clones of a primary tumor, and their chance of achievement is the highest if most or all of them come from the same clone which is extremely unlikely.

Different-clone cells have a tough time equilizing their geno-phenotypical differences while at the same time they both make their best efforts individually to communicate with the watchful microenvironment to convince it to sanction and even cooperate. Their presence as newcomers with their swiftly emerging dynamism of both individualism and groupconflict immediately becomes difficult for the uncooperative microenvironment to deal with, and the required "host measures" emerge to eliminate them by forcing them to dormancy or apoptosis.

The cells of a multi-clone group can get away only when they manage to equalize their differences via their communication which not only conflicts in itself, but also gets disrupted by the microenvironmental forces. Same-clone cells, on the other hand, whose running into each other is mathematically less likely than that of different-clone cells, would be more concurring to team up, more powerful to flourish and more convincing to get the microenvironment's acquiescence.

For the flourishing metastatic group cells, establishing micrometastasis is not a guarantee for a bright future as every new generation becomes more ineffectual than the preceding one. In a "Limited Survival of Early Micrometastases" study titled "Multistep Nature of Metastatic Inefficiency", Luzzi and his colleagues [10] neatly demonstrated that metastatic inefficiency is principally determined by two distinct aspects of cell growth after extravasation: Failure of solitary cells to initiate growth and failure of early micrometastases to continue growth into macroscopic tumors.

\section{Discussion}

In oncogenesis, where an unreserved display of Darwin's Evolution Theory is seen [1], what all we are able to see so far is only a tiny fraction of its happenings and changes reflected to the cancer cellss morphology. And therefore, what all we know today in this scarce provision of the cellss abundant resources and data in a partial display of its rich composition and orchestration, and in its external relations, is quite limited, mostly because our comprehension of it is limited. Our confinement within this limitation, also in other certain fields of clinical and research medicine, render our interpretation of it linearly insufficient, and it often puts us in efficacy and hindrance which we most frustratedly experience in today's Oncology where unavailing scientific beliefs and views archaically continue to feed analytical preoccupations. Whence there is a fundamental reason for us to open wider paths and avenues to "understanding and solving oncogenesis" with rational approaches and cataclysmic insights, and to embrace overall management of the oncologic disease with radical implements. In this regard, we must aim at opening a new, reformative, reconstituting era of oncology not only in the fundementals and basics of universal cancer research and studies, but also in the practice and management of Oncology at clinical and molecular levels where new, better thought of and more effective strategies of oncotherapy are crucially needed.

\section{Competing Interests}

The author declares that he has no competing interest.

\section{References}

1. Darwin CR. On the Origin of Species by Means of Natural Selection, or the Preservation of Favoured Races in the Struggle for Life. John Murray 1859, London.

2. Merlo LM, Pepper JW, Reid BJ, Maley CC. Cancer as an evolutionary and ecological process. Nat Rev Cancer 2006; 6:924-935.3 doi: 10.1038/ nrc2013

3. Pepper J, Findlay CS, Kassen R, Spencer S, Maley C. Cancer research meets evolutionary biology. Evolutionary Applications 2009; 2:62-70. Doi: 10.1111/j.1752-4571.2008.00063.x

4. Graves M, Maley CC. Clonal evolution in cancer. Nature 2012; 481:306313. doi: 10.1038/nature10762

5. Campbell PJ, Yachida S, Mudie $L$ et al. The patterns and dynamics of genomic instability in metastatic pancreatic cancer.Nature 2010; 467:1109-1113. doi: 10.1038/nature09460

6. Yachida S, Jones S, Bozic I et al. Distant metastasis occurs late during the genetic evolution of pancreatic cancer.Nature 2010; 467:1114-1117. doi: 10.1038/nature09515 
7. Klein G. Toward a genetics of cancer resistance. PNAS 2009; 106:859863. doi: $10.1073 /$ pnas.0811616106

8. Podlaha $\mathrm{O}$, Riester M, De $\mathrm{S}$, Michor F. Evolution of the cancer genome. Trends in Genetics 2012; 28(4):155-163. doi: 10.1016/j.tig.2012.01.003

9. Malaise EP, Chavaudra N, Tubiana M. The relationship between growth rate, labelling index and histological type of human solid tumours. Eur J Cancer 1973; 9(4):305-12. doi: 10.1016/0014-2964(73)90099-6

10. Luzzi KJ, MacDonald IC, Schmidt EE, Groom AC. Multistep Natureof Metastatic Inefficiency. Am J Pathol 1998; 153(3):865-873. doi: 10.1016/ S0002-9440(10)65628-3
11. Deisboeck TS, Couzin ID. Collective behavior in cancer cell populations Bioessays 2009;3 1(2):190-7. doi: 10.1002/bies.200800084.

12. Blanpain C. Tracing the cellular origin of cancer. Nature Cell Biology 2013; 15:126-134. doi: 10.1038/ncb2657

13. Casás-Selves $M$, DeGregori J. How cancer shapes evolution, and howevolution shapes cancer. Evolution (N Y) 2011; 4(4):624-634. doi: 10.1007/s12052-011-0373-y 